\title{
Role of Antigen Selectivity in Autoimmune Responses to the Ku (p70/p80) Antigen
}

Westley H. Reeves, Zev M. Sthoeger, and Robert G. Lahita*

The Rockefeller University, New York 10021; *Cornell University Medical Center, New York 10021

\begin{abstract}
Levels of anti-Ku (p70/p80) antibodies were measured longitudinally in sera from four individuals with systemic lupus erythematosus or related disorders. Antibodies to the native Ku antigen ( $70 /$ p80 complex) varied over a range of up to 577-fold. Large fluctuations were also observed in the levels of autoantibodies to several distinct epitopes of the $\mathrm{Ku}$ (p70/p80) antigen. Levels of these individual autoantibody populations generally paralleled one another, suggesting that they are coordinately regulated. A similar pattern of anti-DNA antibody fluctuation was seen in some sera. To examine the possibility that these autoantibodies were generated by polyclonal B cell activation, the levels of anti-Ku (p70/p80) and anti-DNA antibodies were compared to the levels of antibodies to Escherichia coli proteins, tetanus toxoid, and bovine insulin, transferrin, cytochrome $c$, serum albumin, and thyroglobulin. In sera from the same individual, anti-Ku (p70/p80) antibodies were sometimes produced in the complete absence of polyclonal activation, and at other times were accompanied by increased polyclonal activation. Anti-DNA antibody levels more closely paralleled the level of polyclonal activation than did the anti-Ku (p70/p80) levels. These studies suggest that anti-Ku (p70/ p80) antibodies are generated by an antigen-selective mechanism, but that polyclonal activation frequently, although not invariably, accompanies autoantibody production. This observation is consistent with the possibility that polyclonal activation might be secondary to autoantibody production.
\end{abstract}

\section{Introduction}

Antinuclear antibodies are one of the most consistent findings in systemic lupus erythematosus (SLE) ${ }^{1}(1)$. The origin of these autoantibodies, and the explanation of their selectivity for nuclear antigens remain obscure. Although certain healthy individuals produce small amounts of autoantibodies similar to those in sera of individuals with SLE or related diseases (2), overproduction of the same autoantibodies correlates strongly with particular subsets of autoimmune disease $(1,3)$. Whether overproduction of these autoantibodies in disease is the result

Portions of this work were presented to the 1988 annual meeting of the American Rheumatism Association and were published in abstract form (1988. Arthritis Rheum. 31:S65).

Address reprint requests to Dr. Reeves.

Received for publication 20 July 1988 and in revised form 9 February 1989.

1. Abbreviations used in this paper: ds, double-stranded (DNA); MCTD, mixed connective tissue disease; PSS, progressive systemic sclerosis (scleroderma); SLE, systemic lupus erythematosus.

J. Clin. Invest.

(c) The American Society for Clinical Investigation, Inc.

0021-9738/89/08/0562/06 \$2.00

Volume 84, August 1989, 562-567 of non-specific polyclonal B cell activation $(4,5)$, or of a more selective, antigen-driven mechanism involving somatic mutation of immunoglobulin genes (6-9), remains controversial.

In these studies, we assessed the roles of polyclonal activation and antigen-selection in the generation of autoantibodies to the $\mathrm{Ku}(\mathrm{p} 70 / \mathrm{p} 80)$ antigen, a macromolecular complex consisting of $\sim 70,000$ - and $\sim 80,000$-dalton proteins which bind to DNA (10-14). Extremely large amounts of anti-Ku (p70/ p80) autoantibodies are found in sera of certain Americans with SLE, mixed connective tissue disease (MCTD), and progressive systemic sclerosis (scleroderma, PSS) (10), and in Japanese with PSS-polymyositis overlap syndrome (11). The diversity of anti-Ku (p70/p80) antibodies and their fluctuation patterns over time observed in the present studies favor a selective, antigen-driven mechanism for their overproduction and raise the possibility that polyclonal activation might occur secondarily.

\section{Methods}

Patients. Sera were obtained from four female patients diagnosed and treated at The Rockefeller University Hospital. Patients CK and MG had SLE, as defined by the American Rheumatism Association criteria (15), patient JM had MCTD (16), and patient JK had PSS (17).

ELISA for anti-Ku (p70/p80) antibodies. Anti-Ku (p70/p80) antibodies were quantitated by ELISA (10). Microtiter plates were coated with monoclonal anti-Ku (p70/p80) antibody 162-11, and antigen from human K562 cell extract was bound. DNA was dissociated from the immobilized antigen by washing with $0.5 \mathrm{M} \mathrm{NaCl}, 50 \mathrm{mM}$ Tris, $\mathrm{pH}$ 7.5, 2 mM EDTA (18). Diluted human sera were added to the wells for $90 \mathrm{~min}$ at $22^{\circ} \mathrm{C}$, followed by peroxidase-conjugated goat anti-human immunoglobulin antibodies ( $\kappa$ and $\lambda$ light chain specificities, from Tago Inc., Burlingame, CA) for an additional $90 \mathrm{~min}$. Absorbance $(A)$ was read at $490 \mathrm{~nm} 1 \mathrm{~h}$ after adding substrate. The relative amounts of anti-p70/p80 antibodies in individual serum samples from the same patient were determined as follows: serial fivefold dilutions from 1:50 to $1: 3,906,250$ were tested by ELISA, and $A_{490}$ was plotted as a function of serum dilution. The $\log _{5}$ difference in antibody levels was determined from the titration curves of the individual sera.

Levels of other types of antibodies. Levels of anti-double-stranded (ds) DNA antibodies were determined by RIA (19) or ELISA (20). Relative amounts of anti-dsDNA antibodies in individual sera of the same patient were determined from titration curves in ELISA as described above for anti-Ku (p70/p80) antibodies. Anti-tetanus toxoid antibodies were measured by ELISA (21), as were levels of antibodies to the following bovine proteins: insulin, transferrin, cytochrome $c$, serum albumin, and thyroglobulin (all from Sigma Chemical Company, St. Louis, MO). Each antigen was allowed to bind to microtiter plates (Nunc Immunoplate I, from VWR Scientific, San Francisco, CA) at a concentration of $10 \mu \mathrm{g} / \mathrm{ml}$ for $12 \mathrm{~h}$ at $4^{\circ} \mathrm{C}$, before washing, blocking, and incubating the wells for $3 \mathrm{~h}$ with diluted antisera (22). Peroxidase-conjugated goat anti-human immunoglobulin antibodies ( $\kappa$ and $\lambda$ chain-specific) were then added as described above, followed by addition of substrate.

Competition ELISA. Relative amounts of serum autoantibodies to different epitopes of the native $\mathrm{Ku}(\mathrm{p} 70 / \mathrm{p} 80)$ antigen complex were determined by competition ELISA (10) using two murine monoclonal anti-Ku (p70/p80) antibodies reactive with distinct epitopes. Micro- 
titer plates were coated with one monoclonal antibody, and antigen was bound to the coating antibody. The binding of the other monoclonal antibody (labeled with alkaline phosphatase) to the immobilized antigen was then measured in the presence of serial dilutions of serum and the dilution producing $50 \%$ inhibition of binding was taken as a measure of the amount of competing antibody present in the serum.

Immunoblotting. The specificities of human autoimmune sera were analyzed by immunoblotting using p70 and p80 proteins that were affinity-purified from K562 cell extract onto monoclonal antibody 162-11-coated protein A-Sepharose beads (Pharmacia Fine Chemicals, Piscataway, NJ) (10). The washed beads were eluted by boiling $3 \mathrm{~min}$ in SDS sample buffer, analyzed on $10 \%$ preparative SDS-polyacrylamide gels (23), and transferred to nitrocellulose (BA-85, Schleicher \& Schuell, Inc., Keene, NH) (24). The blots were blocked in $150 \mathrm{mM} \mathrm{NaCl}, 50 \mathrm{mM}$ Tris, pH 7.5, 0.02\% $\mathrm{NaN}_{3}$ containing $1 \%$ bovine hemoglobin, incubated with serum (1:500 in blocking solution for 3-12 h), washed, and incubated $3 \mathrm{~h}$ with ${ }^{125} \mathrm{I}$-protein A (New England Nuclear, Boston, MA; $10^{5} \mathrm{dpm} / \mathrm{ml}$ ). After exposure to $\mathrm{X}$-ray film, individual protein bands of equal width were cut from the nitrocellulose, and bound radioactivity was quantitated by gamma counting. Standard curves of counts per minute versus serum concentration were generated for each antigen.

p70 fusion protein. The 70.77 fusion protein consists of the aminoterminal $\sim 110 \mathrm{kD}$ of $\beta$-galactosidase linked to the carboxy-terminal 189 amino acids of p70 (25). Production of the fusion protein by Escherichia coli lysogenic for the recombinant lambda phage was induced by addition of isopropyl $\beta$-D-thiogalactopyranoside (IPTG) to bacterial cultures (26). Lysates from lysogenized $E$. coli Y1089, or control Y 1089 cells were subjected to SDS-PAGE, followed by immunoblotting as described above.

\section{Results}

Examination of serial serum samples from an individual with SLE revealed striking differences in the levels of autoantibodies to the native $\mathrm{p} 70 / \mathrm{p} 80(\mathrm{Ku})$ antigen over time (Fig. 1). These antibodies were present in only small quantities in 5-79 (Fig. 1, indicated by *). The amount of anti-Ku (p70/p80) antibodies in 5-79 serum was arbitrarily assigned a value of $1 \mathrm{U}$, and the amounts of anti-Ku (p70/p80) antibodies in subsequent sera were compared to this standard serum. The anti-Ku (p70/ p80) antibodies had increased 15.4 -fold by $1-80$ (Fig. 1, point $a$ ), 25-fold by $12-80$ (point $b$ ), 106-fold by 1-84 (point $c$ ), and

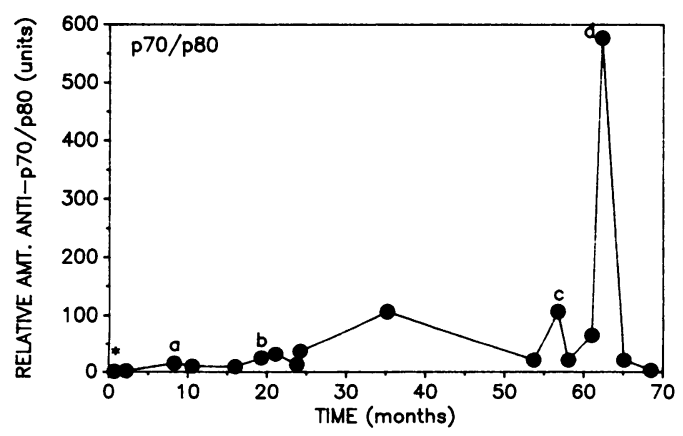

Figure 1. Levels of antibodies to native $\mathrm{Ku}(\mathrm{p} 70 / \mathrm{p} 80)$ complex in CK serum over time. Antibodies to native $\mathrm{Ku}(\mathrm{p} 70 / \mathrm{p} 80)$ were quantitated by ELISA. The level of anti-native $\mathrm{Ku}(\mathrm{p} 70 / \mathrm{p} 80)$ antibodies in serum from 5-79 (indicated by *) was arbitrarily assigned a value of $1 \mathrm{U}$, and amounts of the autoantibodies in other sera were compared to this reference serum. Time points $a-d$ correspond to time points $a-d$ in Fig. 3, and have values of 15.4, 25, 106, and $577 \mathrm{U}$, respectively. 577-fold by 7-84 (point $d$ ), compared to the reference serum. Between these peaks $(a-d)$ of anti-Ku (p70/p80) autoantibodies, the levels declined considerably, suggesting that the autoantibodies were generated intermittently. To investigate the mechanism by which these antibodies were generated, we first examined whether the anti-Ku (p70/p80) autoantibodies in CK sera were monoclonal or multiclonal (Fig. 2, Table I). Immunoblotting of purified p70 and p80 proteins (Fig. $2 \mathrm{~A}$ ) indicated that the autoantibodies were highly specific for p70 until 4-80, when anti-p80 autoantibodies appeared for the first time (Fig. $2 A$, lane 10). Thus, after 4-80, the autoantibodies were reactive with at least two epitopes, one on denatured p70, and the other on denatured p80. Purification of the individual autoantibody populations by elution from immunoblots (27) confirmed that the anti-p70 antibodies were unreactive with $\mathrm{p} 80$, and vice versa (data not shown). Autoantibodies to the 70.77 fusion protein produced a fluctuation pattern similar to that of antibodies to intact p70 on immunoblots (Fig. 2 B). When these autoantibody populations were quantitated (Fig. 3), similarities between the levels of autoantibodies to $\mathrm{p} 80$ (Fig. $3 \mathrm{~A}$ ), p70 (Fig. $3 \mathrm{~B}$ ), and the 70.77 fusion protein (Fig. $3 \mathrm{C}$ ) were obvious. For each peak of anti-Ku (p70/p80) antibodies (points $a-d$, Fig. 1), a corresponding peak of p70, p80, and 70.77 fusion protein antibodies was observed. However, the relative magnitudes of the peaks varied, depending on which population of autoantibodies was measured (compare Fig. 3, $A$ and $B$ ). Autoantibodies to two distinct epitopes of the native $\mathrm{Ku}(\mathrm{p} 70 / \mathrm{p} 80)$ complex were also measured in serial sera from patient CK (Table I) by competition ELISA using native antigen. The autoantibodies measured in these assays are reactive with epitopes of native $\mathrm{Ku}$ (p70/p80), but not the denatured antigen. Levels of antibodies to native $\mathrm{Ku}(\mathrm{p} 70 / \mathrm{p} 80)$ epitopes paralleled the levels of antibodies to denatured p70 and p80.

Autoantibodies to another antigen, dsDNA, displayed a similar pattern of fluctuation (Fig. $3 \mathrm{D}$ ), although some differences were noted. In particular, anti-dsDNA antibodies frequently peaked slightly after the peaks of anti-p70, anti-p80, and anti-70.77 antibodies (Fig. 3, $A-D$, points $a$ and $b$ ). The similarities in the fluctuation patterns of anti-Ku (p70/p80) and anti-dsDNA antibodies suggested that these distinct populations of autoantibodies are coordinately regulated. We therefore investigated the possibility that the coordinate regulation of the different autoantibody populations might be due to intermittent polyclonal B cell activation.

When antibodies to two $E$. coli proteins, of $M_{\mathrm{r}} \sim 56$ and $\sim 86 \mathrm{kD}$ were measured, some similarities with the patterns of variability of anti-Ku (p70/p80) and anti-DNA antibodies were seen (Fig. 3, $E$ and $F$ ). At point $a$ (Fig. 3), a peak of autoantibody levels was accompanied by a peak of antibodies to both $E$. coli proteins. However, at point $c$, the peak of autoantibodies was accompanied by a peak of antibodies to the $56-\mathrm{kD}$, but not the $86-\mathrm{kD} E$. coli protein, and at points $b$ and $d$, there was little or no increase in the levels of either $E$. coli protein. Like anti-dsDNA antibodies, the peak of anti-E. coli antibodies sometimes occurred slightly later than the peak of anti-Ku (p70/p80) antibodies.

The relationship between autoantibody production and polyclonal activation was further investigated by comparing levels of anti-Ku (p70/p80) and anti-dsDNA autoantibodies with levels of antibodies to five bovine proteins (insulin, transferrin, cytochrome $c$, serum albumin, and thyroglobulin), and tetanus toxoid in sera from four individuals (Tables I-IV). 


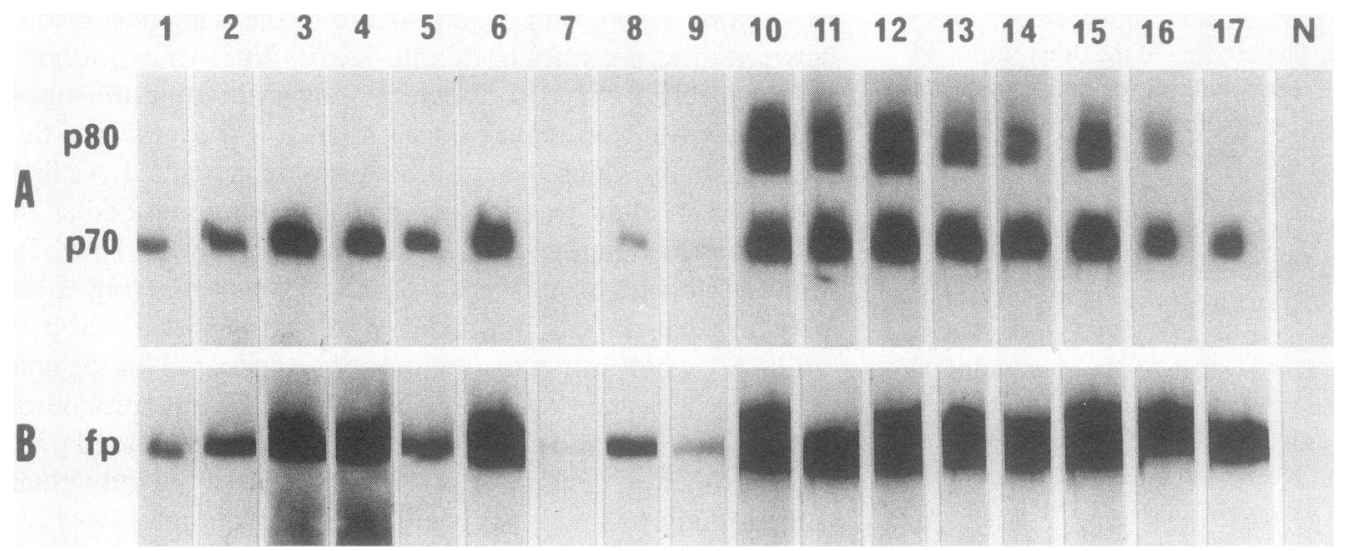

Figure 2. Immunoblot analysis of anti-Ku (p70/p80) antibodies over time. Reactivity of serial CK sera at 1:500 dilution with purified, denatured $\mathrm{p} 70$ and $\mathrm{p} 80$ proteins $(A)$ and with fusion protein 70.77, containing the carboxy-terminal 189 amino acids of p70 (B), was determined. Dates of sera examined correspond to individual data points shown in Figs. 1 and 3. Dates of sera analyzed in lanes 1-17: (1) $5-79,(2) 7-79,(3) 1-80,(4)$

3-80, (5) 8-80, (6) 12-80, (7) 2-81, (8) 4-81, (9) 5-81, (10) 4-82, (11) 10-83, (12) 1-84, (13) 3-84, (14) 6-84, (15) 7-84, (16) 10-84, (17) 1-85. Immunoblot with normal human serum $(N)$ is shown for comparison.

Maximum titers of anti-Ku (p70/p80) antibodies in the four individuals' sera were as follows: CK, > 1:3,906,250; JM, 1:3,906,250; MG, > 1:3,906,250, and JK, 1:156,250. Antibodies to the exogenous proteins were present in low levels in these autoimmune sera, and in the absence of immunization, their levels should be reflective of the general state of polyclonal B cell hyperactivity. Because of the low levels of these antibodies, precise quantitation of their levels by comparing titration curves was not possible, but the absorbance at $490 \mathrm{~nm}$ produced by a 1:50 serum dilution reproducibly gave a qualitative, if only semiquantitative, measure of the level of polyclonal activation. In serial CK sera (Table I), the level of polyclonal activation decreased from 6-80 to $12-80$, as indicated by a decrease in the levels of antibodies to insulin, transferrin, cytochrome $c$, bovine serum albumin, thyroglobulin, and tetanus toxoid. At the same time, anti-Ku (p70/p80) autoantibodies increased from $5.5 \%$ to $71.4 \%$. Thus, between these two points in time, production of anti-Ku (p70/p80) autoantibodies was completely dissociated from the level of polyclonal activation. However, between 3-84 and 7-84, an increase in

Table I. Antibody Levels in CK Sera

\begin{tabular}{lccccc}
\hline & \multicolumn{5}{c}{ Date } \\
\cline { 2 - 6 } \multicolumn{1}{c}{ Antigen } & $6-80$ & $12-80$ & $3-84$ & $7-84$ & $10-84$ \\
\hline Insulin* & 0.36 & 0.23 & 0.28 & 0.73 & 0.30 \\
Transferrin* & 0.24 & 0.18 & 0.25 & 0.40 & 0.20 \\
Cytochrome $c^{*}$ & 0.31 & 0.26 & 0.26 & 0.44 & 0.26 \\
BSA* $_{\text {Thyroglobulin* }}^{*}$ & 0.30 & 0.17 & 0.25 & 0.40 & 0.22 \\
Tetanus* & 0.46 & 0.24 & 0.35 & 0.56 & 0.31 \\
p70/p80 & 0.59 & 0.36 & 0.38 & 0.60 & 0.32 \\
MAb 162 & 5.5 & 71.4 & 32.3 & 100 & 23.3 \\
MAb 111 $^{\S}$ & 400 & 5400 & 3200 & 7500 & 1500 \\
dsDNA & $<50$ & $<50$ & 95 & 220 & 80 \\
& 10.5 & 16.9 & 10.5 & 100 & 27.8 \\
\hline
\end{tabular}

\footnotetext{
${ }^{*} A_{492}$, ELISA.

${ }^{\ddagger}$ Units, from ELISA titration curves. Reference serum $=100 \mathrm{U}$.

$\S 1$ serum dilution required to inhibit binding by $50 \%$ in competition ELISA.
}

anti-Ku (p70/p80) antibodies was accompanied by a parallel increase in the level of polyclonal activation. These results, as well as the findings with $E$. coli proteins, suggest that autoantibody generation is sometimes independent of the production of antibodies to exogenous antigens, and is sometimes accompanied by evidence of polyclonal activation. In general, the levels of anti-dsDNA antibodies correlated better than the levels of anti-Ku (p70/p80) antibodies with the level of polyclonal activation.

The levels of anti-Ku (p70/p80), and anti-dsDNA autoantibodies were compared with the levels of antibodies to exogenous antigens in serial sera from three other patients (Tables II-IV), with results similar to those illustrated by sera from patient CK (Table I). For example, in sera from patient JM, a striking increase in polyclonal activation was observed between 3-85 and 11-86 (Table II), while at the same time, anti$\mathrm{Ku}(\mathrm{p} 70 / \mathrm{p} 80)$ antibodies decreased significantly. The antiDNA antibody levels paralleled the level of polyclonal activation, rather than the anti-Ku (p70/p80) autoantibody levels, further reinforcing the impression that anti-DNA autoantibody production is more closely linked to polyclonal activation than is the production of anti-Ku (p70/p80) antibodies. Similar results were obtained with sera from the other two individuals. Notably, the level of polyclonal activation in sera from patient JK, an individual with PSS, was significantly less than the levels of polyclonal activation detected in sera from the other patients, who had SLE (CK, MG) or MCTD (JM). In addition, the anti-Ku (p70/p80) autoantibody levels displayed considerably less variability in sera from patient $\mathrm{JK}$ than was observed in the other sera.

\section{Discussion}

Polyclonal activation of $B$ cells has been proposed as a mechanism for generating autoantibodies in murine and human lupus $(4,5)$. Alternatively, autoantibodies might arise by antigenic stimulation and somatic mutation of specific B cells (6-9). In the present studies, specific autoantibody levels were compared over time to levels of antibodies to exogenous antigens to assess the role of random, polyclonal activation versus that of antigen selection (28-31) in the production of autoantibodies in human SLE. 

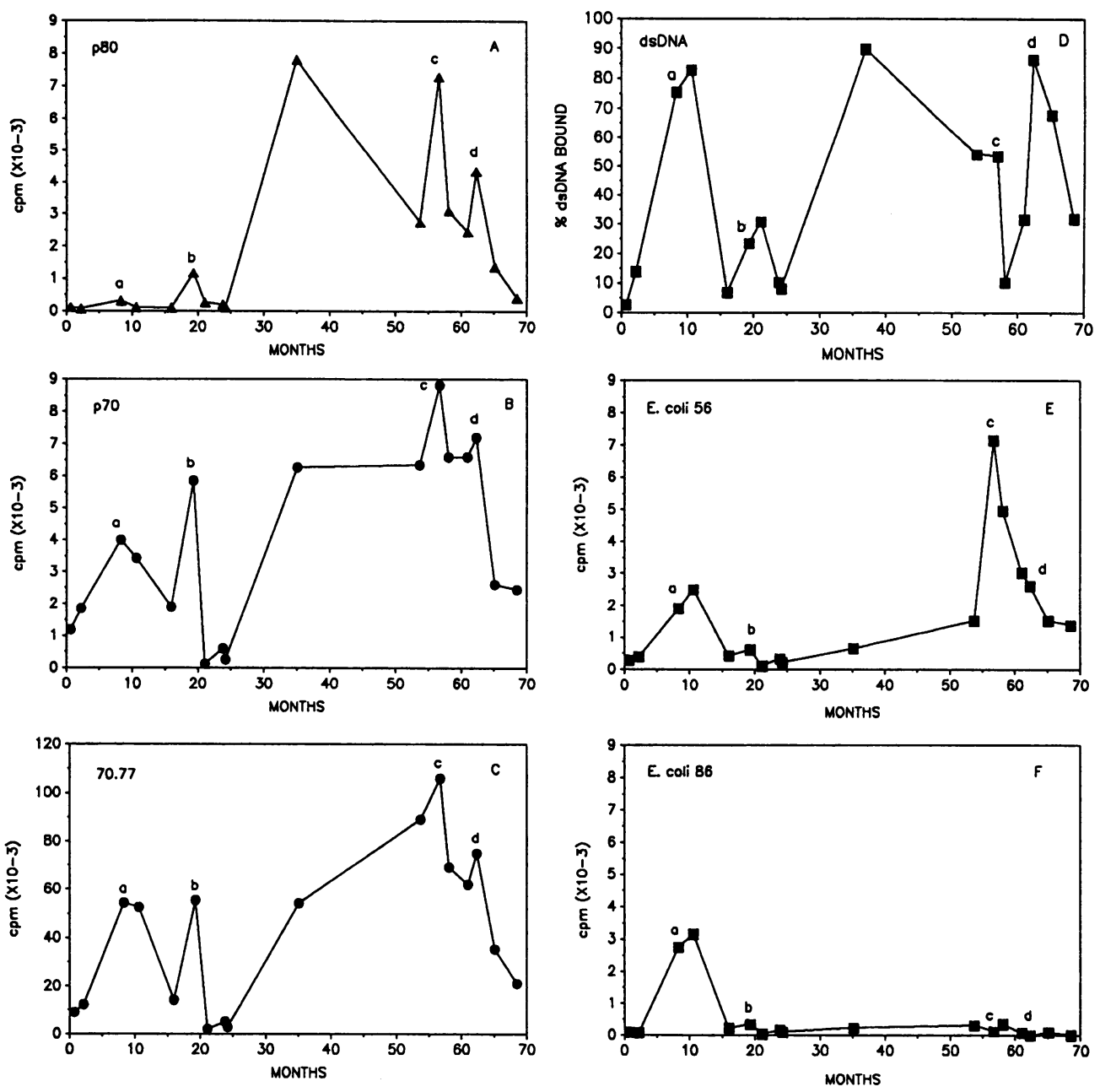

Figure 3. Levels of antibodies to components of the $\mathrm{Ku}(\mathrm{p} 70$ / p80) complex and to $E$. coli proteins in serial CK sera. The same sera analyzed in Figs. 1 and 2 were examined for levels of antibodies to the following: $(A)$ denatured $\mathrm{p} 80,(B)$ denatured $\mathrm{p} 70$, (C) 70.77 fusion protein (containing a major autoepitope of p70), (D) double-stranded DNA, $(E)$ a $56-\mathrm{kD} E$. coli protein, and $(F)$ a 86-kD E. coli protein. Antibody levels were measured by quantitative immunoblotting $(A-C, E$ and $F)$ or by RIA $(D)$.

We observed parallel fluctuations in the levels of autoantibodies to several independent epitopes of the $\mathrm{Ku}(\mathrm{p} 70 / \mathrm{p} 80)$ autoantigen, including epitopes of denatured p70 and p80, as well as two distinct epitopes of the native $\mathrm{Ku}(\mathrm{p} 70 / \mathrm{p} 80)$ complex. Anti-DNA antibodies frequently displayed parallel fluctuations, but the peak levels of these antibodies often occurred several weeks after the peaks of anti-Ku (p70/p80) autoanti-

Table II. Antibody Levels in JM Sera

\begin{tabular}{lccccc}
\hline & \multicolumn{5}{c}{ Date } \\
\cline { 2 - 6 } \multicolumn{1}{c}{ Antigen } & $12-84$ & $1-85$ & $3-85$ & $11-86$ & $12-86$ \\
\hline Insulin* & 0.41 & 0.34 & 0.48 & 1.24 & 1.22 \\
Transferrin* & 0.23 & 0.21 & 0.22 & 0.61 & 0.67 \\
Cytochrome $c^{*}$ & 0.30 & 0.20 & 0.27 & 0.79 & 0.65 \\
BSA $^{*}$ & 0.21 & 0.21 & 0.23 & 0.61 & 0.56 \\
Thyroglobulin* & 0.33 & 0.30 & 0.37 & 0.61 & 0.65 \\
Tetanus* & 0.22 & 0.21 & 0.25 & 0.52 & 0.53 \\
p70/p80 & 100 & 32.3 & 38.5 & 14.5 & 12.3 \\
dsDNA & 100 & 52.6 & 52.6 & 71.4 & 100 \\
& & & & & \\
\end{tabular}

* $A_{492}$, ELISA.

‡ Units, from ELISA titration curves. Reference serum $=100 \mathrm{U}$. bodies. Surprisingly, peaks of anti-Ku (p70/p80) autoantibodies were sometimes accompanied by peaks of polyclonal activation as determined by measuring levels of several exogenous antigens, but at other times, were completely independent of the level of polyclonal activation. At times, anti-Ku (p70/p80) autoantibodies increased dramatically at the same time as a significant decrease in the level of polyclonal activation

Table III. Antibody Levels in MG Sera

\begin{tabular}{lccccc}
\hline & \multicolumn{5}{c}{ Date } \\
\cline { 2 - 6 } \multicolumn{1}{c}{ Antigen } & $1-86$ & $2-86$ & $5-86$ & $9-86$ & $3-87$ \\
\hline Insulin* & 0.71 & 0.39 & 0.32 & 0.28 & 0.36 \\
Transferrin* & 0.20 & 0.40 & 0.29 & 0.20 & 0.24 \\
Cytochrome $c^{*}$ & 0.23 & 0.20 & 0.42 & 0.34 & 0.33 \\
BSA* $_{\text {Thyroglobulin* }}^{*}$ & 0.19 & 0.16 & 0.39 & 0.35 & 0.30 \\
Tetanus* & 0.29 & 0.22 & 0.40 & 0.24 & 0.33 \\
p70/p80 & 0.62 & 0.50 & 0.80 & 0.60 & 0.67 \\
dsDNA & 100 & 10.5 & 20.0 & 38.5 & 14.5 \\
& 100 & 260 & 190 & 220 & 190 \\
\hline
\end{tabular}

* $A_{492}$, ELISA.

‡ Units, from ELISA titration curves. Reference serum $=100 \mathrm{U}$. 
Table IV. Antibody Levels in JK Sera

\begin{tabular}{lccccc}
\hline \multirow{1}{*}{\multicolumn{1}{c}{ Antigen }} & \multicolumn{5}{c}{ Date } \\
\cline { 2 - 6 } & $3-84$ & $7-84$ & $8-84$ & $9-84$ & $10-84$ \\
\hline Insulin* & 0.09 & 0.11 & 0.14 & 0.15 & 0.13 \\
Transferrin* & 0.13 & 0.18 & 0.18 & 0.21 & 0.22 \\
Cytochrome $c^{*}$ & 0.16 & 0.20 & 0.23 & 0.23 & 0.22 \\
BSA $^{*}$ & 0.13 & 0.20 & 0.17 & 0.16 & 0.16 \\
Thyroglobulin* $^{*}$ & 0.15 & 0.28 & 0.18 & 0.26 & 0.20 \\
Tetanus* & 0.13 & 0.19 & 0.16 & 0.20 & 0.17 \\
p70/p80 $^{\ddagger}$ & 38.5 & 38.5 & 38.5 & 45.5 & 100 \\
dsDNA & Neg & Neg & Neg & Neg & Neg \\
& & & & & \\
\hline
\end{tabular}

* $A_{492}$, ELISA.

${ }^{\ddagger}$ Units, from ELISA titration curves. Reference serum $=100 \mathrm{U}$.

Abbreviation: Neg, negative.

(Tables I-IV). The magnitude of the increases in anti-Ku (p70/p80) autoantibody levels also speaks strongly against the possibility that these autoantibodies were generated by polyclonal activation. For example, the 577-fold increase of anti$\mathrm{Ku}(\mathrm{p} 70 / \mathrm{p} 80)$ autoantibodies observed in patient CK serum (Fig. 1) could not have been accompanied by a comparable increase in total immunoglobulin levels. It should also be mentioned that the titers of anti-Ku (p70/p80) autoantibodies were considerably higher than the anti-DNA titers or the levels of antibodies to exogenous proteins ( $E$. coli proteins, tetanus toxoid, and bovine proteins). Taken together, these observations suggest that the selective, intermittent activation of anti$\mathrm{Ku}(\mathrm{p} 70 / \mathrm{p} 80)$ autoantibody production may sometimes be accompanied (or followed) by secondary polyclonal activation. The reason that this is not always the case remains unclear.

Secondary polyclonal activation has been observed in several other situations. Resting B lymphocytes can be polyclonally activated to differentiate into antibody-secreting cells when cultured with MHC-compatible, antigen-specific T cells plus the antigen for which the $T$ cells are specific (32). Similarly, immunization with tetanus toxoid can induce polyclonal activation (33), as can homologous immune complexes in vitro (34). Conceivably, the immune response to $\mathrm{Ku}(\mathrm{p} 70 / \mathrm{p} 80)$ might lead to polyclonal activation through analogous mechanisms.

Another feature of the autoimmune response to $\mathrm{Ku}$ (p70/ p80) is the tight linkage of anti-p70 antibody production with anti-p80 production, and to a lesser degree, with anti-DNA production (Fig. 2). Reactivity with each of these components consists primarily of IgG autoantibodies (our unpublished observation), suggesting the involvement of $T$ cells. Since p70, p80, and DNA are components of the same macromolecular complex (10), it is tempting to speculate that the coordinate regulation of autoantibodies to these components might be related to a single population of $T_{h}$ cells providing help for each of the autoantibody populations involved. There is precedent for such a mechanism in the production of antibodies to certain viruses $(35,36)$. For example, production of antibodies to the influenza virus hemagglutinin is supported equally well by $T_{h}$ cells specific for the hemagglutinin, matrix protein, or nucleoprotein (35). Thus, in the case of a macromolecular complex, $T_{h}$ cells appear to be capable of providing help for populations of B cells secreting antibodies reactive with epitopes that are not covalently linked to the $T$ cell epitopes involved. This phenomenon might explain the linkage of antip70 and anti-p80 autoantibodies, and might also be responsible for the linked production of autoantibodies reactive with several different components of other macromolecular complexes (31).

In conclusion, our findings suggest that autoantibodies to different components of the $\mathrm{p} 70 / \mathrm{p} 80(\mathrm{Ku})$ complex are coordinately regulated, and that their production is not due to polyclonal activation. However, a link with polyclonal activation is apparent. Further studies will be necessary to define the nature of this link between autoantibody production and polyclonal activation. The simplest, but not the only, explanation for this link is that polyclonal activation is secondary to the autoimmune response.

\section{Acknowledgments}

We thank Henrietta Carbonaro, Elena Kissin, and David Tirschwell for technical assistance, and Dr. Lloyd Mayer for providing sera from patient JK.

This work was supported by grant AR 01499 from the U.S. Public Health Service, and by a General Clinical Research Center grant (RR-00102) from the National Institutes of Health. Dr. Reeves is a recipient of an Arthritis Investigator Award from the Arthritis Foundation. Dr. Sthoeger is a fellow of the Lupus Foundation of New York.

\section{References}

1. Tan, E. M. 1982. Autoantibodies to nuclear antigens (ANA): their biology and medicine. Adv. Immunol. 33:167-240.

2. Gaither, K. K., O. F. Fox, H. Yamagata, M. J. Mamula, M. Reichlin, and J. B. Harley. 1987. Implications of anti-Ro/Sjogren's syndrome A antigen autoantibody in normal sera for autoimmunity. $J$. Clin. Invest. 79:841-846.

3. Maddison, P. J., and M. Reichlin. 1977. Quantitation of precipitating antibodies to certain soluble nuclear antigens in SLE. Arthritis Rheum. 20:819-824.

4. Klinman, D. M., and A. D. Steinberg. 1987. Systemic autoimmune disease arises from polyclonal B cell activation. J. Exp. Med. 165:1755-1760.

5. Smith, H. R., and A. D. Steinberg. 1983. Autoimmunity: a perspective. Annu. Rev. Immunol. 1:175-210.

6. Davidson, A., R. Shefner, A. Livneh, and B. Diamond. 1987. The role of somatic mutation of immunoglobulin genes in autoimmunity. Annu. Rev. Immunol. 5:85-108.

7. Query, C. C., and J. D. Keene. 1987. A human autoimmune protein associated with U1 RNA contains a region of homology that is cross-reactive with retroviral p30gag antigen. Cell. 51:211-220.

8. Oldstone, M. B. A. 1987. Molecular mimicry and autoimmune disease. Cell. 50:819-820.

9. Plotz, P. H. 1983. Autoantibodies are anti-idiotype antibodies to antiviral antibodies. Lancet. 2:824-826.

10. Reeves, W. H. 1985. Use of monoclonal antibodies for the characterization of novel DNA-binding proteins recognized by human autoimmune sera. J. Exp. Med. 161:18-39.

11. Mimori, T., M. Akizuki, H. Yamagata, S. Inada, S. Yoshida, and M. Homma. 1981. Characterization of a high molecular weight acidic nuclear protein recognized by autoantibodies from patients with polymyositis-scleroderma overlap. J. Clin. Invest. 68:611-620.

12. Francoeur, A. M., C. L. Peebles, P. T. Gompper, and E. M. Tan. 1986. Identification of the $\mathrm{Ki}(\mathrm{Ku}, \mathrm{p} 70 / \mathrm{p} 80)$ autoantigens and analysis of anti-Ki autoantibody reactivity. J. Immunol. 136:16481653. 
13. Yaneva, M., R. Ochs, D. K. McRorie, S. Zweig, and H. Busch. 1985. Purification of an 86-70 kDa nuclear DNA-associated protein complex. Biochim. Biophys. Acta. 841:22-29.

14. Mimori, T., and J. A. Hardin. 1986. Mechanism of interaction between Ku protein and DNA. J. Biol. Chem. 261:10375-10379.

15. Tan, E. M., A. S. Cohen, J. F. Fries, A. T. Masi, D. J. McShane, N. F. Rothfield, J. Green Schaller, N. Talal, and R. J. Winchester. 1982. The 1982 revised criteria for the classification of systemic lupus erythematosus. Arthritis Rheum. 25:1271-1277.

16. Sharp, G. C., W. S. Irvin, E. M. Tan, R. G. Gould, and H. R. Holman. 1972. Mixed connective tissue disease: an apparently distinct rheumatic disease syndrome associated with a specific antibody to an extractable nuclear antigen (ENA). Am. J. Med. 52:148-159.

17. Subcommittee for Scleroderma Criteria of the Americal Rheumatism Association Diagnostic and Theraputic Criteria Committee. 1980. Preliminary criteria for the classification of systemic sclerosis (scleroderma). Arthritis Rheum. 23:581-590.

18. Reeves, W. H. 1987. Antinuclear antibodies as probes to explore the structural organization of the genome. J. Rheumatol. 14(Suppl. 13):97-105.

19. Wold, R. T., F. E. Young, E. M. Tan, and R. S. Farr. 1968. Deoxyribonucleic acid antibody: a method to detect its primary interaction with deoxyribonucleic acid. Science (Wash. DC). 161:806-807.

20. Eaton, R. B., G. Schneider, and P. H. Schur. 1983. Enzyme immunoassay for antibodies to native DNA. Specificity and quality of antibodies. Arthritis Rheum. 26:52-62.

21. Chiorazzi, N., R. L. Wasserman, and H. G. Kunkel. 1982. Use of Epstein-Barr virus-transformed B cell lines for the generation of immunoglobulin-producing human B cell hybridomas. J. Exp. Med. 156:930-935.

22. Giallongo, A., L. Kochoumian, and T. P. King. 1982. Enzyme and radioimmunoassays for specific murine IgE and IgG with different solid phase immunosorbants. J. Immunol. Methods. 52:379-393.

23. Weber, K., and M. Osborn. 1975. Proteins and sodium dodecyl sulfate: molecular weight determination on polyacrylamide gels and related procedures. In The Proteins. H. Neurath and $\mathrm{R}$. L. Hill, editors. Academic Press, Inc., New York. 179-223.

24. Towbin, H., T. Staehelin, and J. Gordon. 1979. Electrophoretic transfer of proteins from polyacrylamide gels to nitrocellulose sheets: procedure and some applications. Proc. Natl. Acad. Sci. USA. 76:4350-4354.

25. Reeves, W. H., and Z. M. Sthoeger. 1989. Molecular cloning of
cDNA encoding the p70 (Ku) lupus autoantigen. J. Biol. Chem. 264:5047-5052.

26. Young, R. A., and R. W. Davis. 1983. Efficient isolation of genes by using antibody probes. Proc. Natl. Acad. Sci. USA. 80:11941198.

27. Smith, D. E., and P. E. Fisher. 1984. Identification, developmental regulation, and response to heat shock of two antigenically related forms of a major nuclear envelope protein in Drosophila embryos: application of an improved method for affinity purification of antibodies using polypeptides immobilized on nitrocellulose blots. $J$. Cell Biol. 99:20-28.

28. Fisher, D. E., W. H. Reeves, R. Wisniewolski, R. G. Lahita, and N. Chiorazzi. 1985. Temporal shifts from Sm to ribonucleoprotein reactivity in systemic lupus erythematosus. Arthritis Rheum. 28:1348-1355.

29. McCarty, G. A., J. R. Rice, M. L. Bembe, and D. S. Pisetsky. 1982. Independent expression of autoantibodies in systemic lupus erythematosus. J. Rheumatol. 9:691-695.

30. Bonfa, E., S. J. Golombek, L. D. Kaufman, S. Skelly, H. Weissbach, N. Brot, and K. B. Elkon. 1987. Association between lupus psychosis and anti-ribosomal $\mathrm{P}$ protein antibodies. N. Engl. J. Med. 317:265-271.

31. Hardin, J. A. 1986. The lupus autoantigens and the pathogenesis of SLE. Arthritis Rheum. 29:457-460.

32. DeFranco, A. L., J. D. Ashwell, R. H. Schwartz, and W. E. Paul. 1984. Polyclonal stimulation of resting B lymphocytes by antigen-specific T lymphocytes. J. Exp. Med. 159:861-880.

33. Welch, M. J., S. Fong, J. Vaughan, and D. Carson. 1983. Increased frequency of rheumatoid factor precursor B lymphocytes after immunization of normal adults with tetanus toxoid. Clin. Exp. Immunol. 51:299-304.

34. Morgan, E. L., and W. O. Weigle. 1983. Polyclonal activation of murine B lymphocytes by immune complexes. J. Immunol. 130:1066-1070.

35. Scherle, P. A., and W. Gerhard. 1986. Functional analysis of influenza-specific helper $T$ cell clones in vivo: $T$ cells specific for internal viral proteins provide cognate help for B cell responses to hemagglutinin. J. Exp. Med. 164:1114-1128.

36. Milich, D. R., A. McLachlan, G. B. Thornton, and J. L. Hughes. 1987. Antibody production to the nucleocapsid and envelope of the hepatitis B virus primed by a single synthetic T cell site. Nature (Lond.). 329:547-549. 